\title{
Leadership Development for International Crises Management: The Whole Person Approach
}

\author{
By Dr Ifti Zaidi, Cranfield University and Dr Blanka Bellak, Leadership Associates
}

\begin{abstract}
Leadership development (LD) is critical in peacebuilding and crisis management where leadership decisions have far-reaching consequences. As organisations navigate turbulence, agile leaders who can deal with information extremes, take critical decision and deliver change are needed. We find contemporary LD approaches are not conceptually geared to deliver such leaders. From a development perspective, the problem lies in the preponderance of reductionist ideas; an overwhelming focus on managerial skills and competencies; and a short-term outlook on development that diminishes the value of leadership courses. This exploratory paper emphasises the value of LD and proposes a rethink in how LD is approached at individual and organisational levels. A holistic, flexible and longitudinal approach - the Whole Person Approach (WPA) - is proposed that encourages individuals and organisations to work jointly towards LD. WPA is equally relevant for other sectors and organisations where volatility, uncertainty, complexity and ambiguity affect positive change.
\end{abstract}

Keywords: International Crisis Management, Leadership Development, Whole Person

Approach, Complexity

\section{Introduction and Background}

In his address to the UN General Assembly in September 2018, the UN Secretary General observed that ' 21 st century challenges outpace 20th century institutions and mind-sets' (Guterres, 2018), a remark that echoes back two decades to similar concerns raised by scholars, international, organisations and corporations (OECD, 2001; World Bank, 1997). Genovese (2016) suggests we live in an age of hyper-change, and while organisations have learned to adapt to external change in the past, hyper-change will test future leadership to its limits. To deal with such challenges, Tal and Gordon (2016) suggest that we need to move away from the idea of the omnipotent heroic leader and towards a more "distributed" concept, embracing wider ownership of responsibilities as posited over two decades ago by the World Bank (1997). These observations are particularly relevant in international crisis management (ICM) where building multi-agency collaboration, networking and cooperation go hand-in-hand in dealing with complexity, ambiguity and uncertainty.

ICM has become a permanent feature of international relations; it is both complex and controversial due to the nature of conflicts and crises but also the nature of actors. ICM includes civilian crisis management; humanitarian aid and assistance; humanitarian intervention; peace-support; peacekeeping; peacebuilding; and peace-making (Houben, 2005). The scope of ICM today has expanded to include civilian-led initiatives (Tardy, et al., 2017 , p. 3) and is very different from the military-like interventions of the 1990s. While there are more and more civilians engaged in conflict management, we observe that the increase in civilian led missions does not manifest a corresponding growth in leadership development (LD). Kaufman (1996) observed, that ICM, instead of providing a solution, often becomes an intractable part of the problem. The Bosnian Civil War (1989-1996) is a case in point. For the UN and the European Union, it was the first real post-Cold War test of ICM and exposed 
myriad shortfalls ranging from legal and structural issues to leadership and management in interconnected complex systems.

The Bosnian Civil War, part of a wider crisis in the Balkans in the 1990s, had roots that can be traced back to the Christian schism of 1054 when the Orthodox Byzantine and Roman Catholic Churches split, redefining ethnical and faith-based frontiers. The Ottoman conquest of the region after the battle of Kosovo Field (1389) added yet another dimension (Mojzes, 2016). The collapse of Yugoslavia, a violent and ugly spike within the wider crises following the death of Marshall Tito in May 1980, is an example of unresolved and recurring problems. The UN humanitarian intervention in the conflict exposed soldiers, civilian staff and leaders at different levels to the new complexities and inexplicable emergent behaviours of actors in a conflict that made even basic humanitarian intervention a wicked problem. Rittel and Webber describe wicked problems as unsolvable, unbounded issues that are socially or culturally constructed, lack clarifying traits and are thus difficult to ring-fence. Such problems follow no rules, are intractable due the number of factors and opinions involved, are always connected to other problems and, therefore, generally impossible to define (1973, p. 160). In the spring of 1993, soldiers and commanders of a British unit faced unforeseen moral dilemmas that drove a wedge between the mission objectives and individual conscience (Watters, 2019). Neutrality, as it then applied, required that soldiers should not intervene in the fighting at any cost. In the spring of 1993 during a spate of house to house clearance by armed gangs, a military patrol opted to save human life by attempting to evacuate civilians from imminent danger and in doing so, they knowingly violated the principle of neutrality Watters (2019). In trying to do the morally right thing, the patrol consciously and willingly exposed themselves to formal disciplinary action. Military training had not prepared these soldiers or their leaders for the kind of ethical and moral challenges they found themselves dealing with. As the system adapted to interventions at all levels from the grand strategic to the business of delivering aid in the field, the disconnects and inconsistencies in principles and practice, and between humanitarian support and humanitarian consequences continued to expand. Lessons gleaned from spring and summer of 1993 in the Balkans, influence international law and UN operations to the present day; creating formal ICM space for regional organisation, non-governmental organisations and local volunteer. Organisation engaged in peacebuilding and ICM need better leadership and investment in LD.

\section{LD is an intentional, forward-looking process aimed at preparing agile and adaptive leaders who can deliver leadership and change in complex systems. In an increasingly} complex world, Kotter argued that organisations are over-managed and under led (2012, p. 30). We reiterate this view and find a predominance of reductionist approaches; a short-term outlook on LD within civil organisations; and the military, while taking a longitudinal approach, only partially focuses on ICM. Continuing the current practice of under-investing in the capacity development of leaders is short-sighted, irresponsible and incompatible with the concept of Duty of Care as recognised by the EU (EEAS, 2017, p. 6; Merkelbach, 2017). We agree with Oddou and Mendenhall (2018) that contemporary LD approaches are based on an array of courses and workshops that are management oriented but fall short of addressing the leadership needs for ICM. A unifying framework that staff and organisations could use to forecast and pursue development needs is missing. This exploratory paper addresses the challenge of balancing LD across the breadth and depth of organisational and individual needs within the context of ICM and proposes a novel approach to deal with the deficit. We briefly look at the ICM context and survey contemporary approaches to LD within the EU. Drawing on best practices across sectors, we advance the Whole Person Approach (WPA) as a guiding framework for LD that individuals and organisations can apply. 


\section{International Crises Management Context and Leadership Development}

Observing an international power vacuum after the collapse of the Soviet Union and the resulting 'disorder' that followed, Barber described the world as volatile, uncertain, complex and ambiguous (VUCA) (1992, p. 8). This acronym combined two challenges for defence and security: first, an organisation's ability to pace internal development with changes in the external environment (Bennins \& Nanus, 1985); and second, an unforeseen set of external challenges emerging out of the unstable and uncertain environment within which the US military found itself in the early 1990s. The contemporary usage of VUCA has wider application and includes interdependent connected systems, disruptive technologies, globalisation and what we see as the new "global-social"- the collective power and influence of social media - to name a few. For LD we see VUCA as the transition from known to unknown, possibly unknowable threats and challenges; and the ambiguity that mirrors across peace and security contexts within ICM. In this sense, LD is about increasing the individual's or collective's ability to deal with complexity, enhancing their potential and supporting engagement with others towards achieving collective objectives or driving change (Santana, 2009) for peace and development in general and ICM in particular.

ICM is an example par excellence of the deep, systemic challenges (Senge, 2006; Atree, et al., 2018) that outpace institutions and mind-sets. ICM sits within a complex adaptive system - 'open, evolutionary aggregates whose components (or agents) are dynamically interrelated and who are cooperatively bonded by common purpose or outlook' (Uhl-Bein, et al., 2007). Complex adaptive systems are non-linear, dynamic systems that evolve around entities consisting of many diverse, autonomous and interrelated agents. These entities learn from experience, are interdependent, interconnected, and constantly adjusting to changes in the environment. Small changes in a subsystem can have significant effects; implying that perfect knowledge of individual parts in a subsystem is insufficient for predicting resultant whole-ofsystem behaviour. Issues addressed in ICM are difficult to conceptualise and can be described as both adaptive (Heifetz, et al., 2009) and, what Rittel and Webber (1973) call 'wicked'. Such problems evolve with every intervention and often appear to go away but are not actually solved but re-solved repeatedly (Grint, 2008). Wicked problems have emergent qualities and behaviours (Allen, 2018) that are often missed. In social systems, this emergence embraces struggle over diverse ideas, "the reformation of existing elements that are qualitatively different from the original elements; and self-organisation." (Uhl-Bein, et al., 2007, p. 308).

The connection between adaptive organisations and leadership is well recognised (Nadler \& Tushman, 1990; Gibson \& Tarrant, 2010; McLay, 2014; Uhl-Bein, et al., 2007). ICM, like any commercial organisation, requires leaders able to deal with turbulence in the organisational, team and individual contexts. Tano finds that 'agile leaders are creative thinkers with a deep sense of purpose', are architects of agile teams and build agile organisations. (2006, p. 9). In today's VUCA world, agile leaders able to deal with extremes of information, capable of taking critical decisions and delivering change proactively, are needed. This is possible through a holistic and longitudinal approach to LD. There exist conflicting views on agency, the value of individualistic focus, group context or social orientation- (Edwards, et al., 2013) to LD. We argue that, it is not only the conflicting approaches or focus on agency but a preponderance of reductionist ideas, an overwhelming focus on managerial skills and competencies, and a short-term outlook on development that affect the quality and value of contemporary LD approaches. Leaders at all levels need a more formal and structured, yet flexible and non-prescriptive way to approach their own development. They must prepare themselves for situations of extreme emotional stress, 
internal and external noise and still delivering effective management and leadership to their organisations.

\section{Leadership and Leadership Development?}

To develop leaders, we need to understand leadership. The terms leadership and management are often used interchangeably. Albeit interconnected, leadership and management are part of different systems of action and therefore require different approaches for development. Management is a process driven by a pursuit for efficiency, effectiveness and upward accountability to formal authority. The manager-staff relationship is, what Northouse describes as a 'unidirectional authority relationship' (2019, p. 15). As everything has a clear purpose, a clear place in the system, and progressions are predictable, management effectiveness can be reduced to skills and competences related to agreed processes and creative problem solving. Managers higher up in the organisation are more strategic but the focus on effectiveness, efficiency and accountability constrains thinking and action.

Leadership, on the other hand, is a multidirectional influence relationship (Northouse, 2019, p. 15) that deals with change and movement (Kotter, 2001). Short of the horizon, within the space that is more predictable, change is premised on what needs to be done for organisational success and survival. Beyond the horizon, the zone of ambiguity and uncertainty expands and the focus shifts to vision - the long-term direction for organisation and more significantly, people within the organisation.

Leadership theory is a natural starting point for designing the 'why, what and how' of LD; however, a universal, cogent and coherent set of theories that clarify the discipline and define leadership is not possible (Latham, 2014). Bennis and Goldsmith (2010) also challenge the notion of a general reflective theory of leadership in the face of 'pervasive incapacity of organisations' and chronic crisis of governance in a complex and changing world. Zyl (2019) echoes this in the context of peace leadership. Oddou and Mendenhall (2018) observe that in an interdependent world, leaders must work with complexity and draw on the experience of foreign partners who are more aware of the cultural milieu to create strategic alliances. Leadership theories have been reflective by nature and tend to remain fixated on hierarchical, top-down industrial age bureaucratic frameworks (Gronn, 2000; Uhl-Bein, et al., 2007) and treat LD as the development of skills and competencies.

Leadership cannot exist without people - the followers, including other leaders - to influence; and can be seen as a relationship between two or more individuals in a system (Day, 2014). Combining relational and complexity dimensions with a more widely agreed idea of leadership as influence, we define leadership in organisations as the art of influence and nurturance of positive changes in a complex adaptive system. A variety of approaches may be needed for effective leadership in ICM and no single theory or approach, as Bennis and Goldsmith (2010) observe for the corporate world, sufficiently encompasses the complexity. Reviewing the whole range of theories is beyond the scope of this paper, we now take a closer look at three that, in our opinion, are particularly relevant to the ICM context:

\section{Vertical LD}

Vertical development theories differentiate between horizontal development- doing things better - and vertical development - enhancing thinking abilities and mind-sets (Petrie, 2014b). A common feature in vertical development is the expansion of consciousness or worldview in the individual and the system. These theories build on developmental psychology, associated with the state encompassing feelings, values, motivations, neurological activation, belief systems, learning systems, and theories of leadership appropriate for that state (Wilber, 2000b, p.5). 


\section{Complexity Leadership Theory}

Recognising limitations of traditional leadership theories with their top-down and simplistic view of the leadership process, complexity leadership theory attempts to address the complex adaptive needs of organisations (Lichtenstein, et al., 2006; Uhl-Bein, 2006). The theory focuses on leadership in 'organizations dealing with rapidly changing, complex problems in the overlapping hierarchies linked in an interactive network' (Tal \& Gordon, 2016, p. 260). Uhl-Bein (2007) suggests that certain interactions within a social network produce nonlinear impact on subsequent interactions; in the very source of volatility, uncertainty and ambiguity and in complex ICM (Watters, 2019). Complexity leadership embraces endogenous, timedependent perspective of change in social systems and explains how new social structures come into existence (Lichtenstein, et al., 2006), and therefore has greater utility in ICM.

\section{Adaptive Leadership}

Connecting problem typologies with leadership styles is not new. Girnt (2008), for example, proposes leadership and management as ways to approach wicked and tame problems - those that have technical solutions, even though they may be complex-respectively. He introduces a third category of problems, the 'critical problem' - one that requires urgent decisions because of the consequences attached to delaying action. Grint suggests command (authoritative decision making), leadership (consultative approach, asking the right question) and management (scientific prescription) as the approaches most suited to critical, wicked and tame problems respectively. Heifetz and Linsky (2002), using an organisational prism, take a functional view of wicked problems and reframe these as adaptive; proposing a pansystem view and a proactive approach. Proponents of Adaptive Leadership suggest that the theory provides a practical framework for organisational change in a complex world (Heifetz, et al., 2009). In ICM situations, we believe Adaptive Leadership complements complexity leadership theory but needs additional 'plug-ins' as most approaches, while incorporating followership interactions, remain top-down.

\section{Spheres of Leadership: Complexity, Decision and Action}

From the nature of wicked problems within complex adaptive systems, the need for agility and adaptive leadership as also posited in complexity leadership theory we conclude that leadership and its effectiveness are the sum of five interconnected spheres of influence as explained below. We propose that LD must address development both within and across these spheres:

Turbulence: the existence or emergence of opportunities; opposing intelligent mindsets; fog and benign or active friction - the net sum of threats, opportunities and VUCA to an organisation's context.

People: Relationship and influence without people is meaningless. people are the common denominator for purpose, relationship and influence. Leadership is thus directed at people and for people, moving them and the organisation towards a better future. The people sphere includes follower, peers and other leader.

Vision: This is the organisation's future direction and is manifested in beliefs, values, goals and actions. The vision serves as a source of inspiration and as a compass that fashions organisational development and decisions. The vision is meaningless unless it is equally connected to people, values, mission and objectives.

Change: Leaders deliver change that extends to systems, organisations and individuals. Change occurs in the physical domain, but mind-sets are equally important. 
Leader: The leader sphere captures mind-set, distal and proximal attributes (Zaccaro, et al., 2004), world-view, cognitive biases and other internal influences that affect reasoning, and drive decisions. Leadership, we argue, is a unique dialectic and thus has a subjective quality in every leader-follower relationship.

Leadership Sweet-spot: From a design perspective, the leadership sweet-spot depicts the scope and direction of leadership development; whereas, from an evaluation standpoint, it is the existential product of strengths and weaknesses in each of the five spheres above. Every leader - the individual with unique distal and proximal attributes - gives leadership a unique individual quality. The leadership sweet spot is equally concerned with the needs of an individual within an organisation and their personal development. As we move from design to reality, the leadership exhibits emergent qualities and becomes more complicated to measure or quantify; particularly since a return on investment is not immediate, unlike developing skills and competencies which can be measured immediately. In organisations, the leadership sweet-spot must be seen from an individual as well as collective context because leadership today is no longer heroic but about a collective of leaders, and followers.

The relationship is illustrated in figure 1 below $^{1}$ :

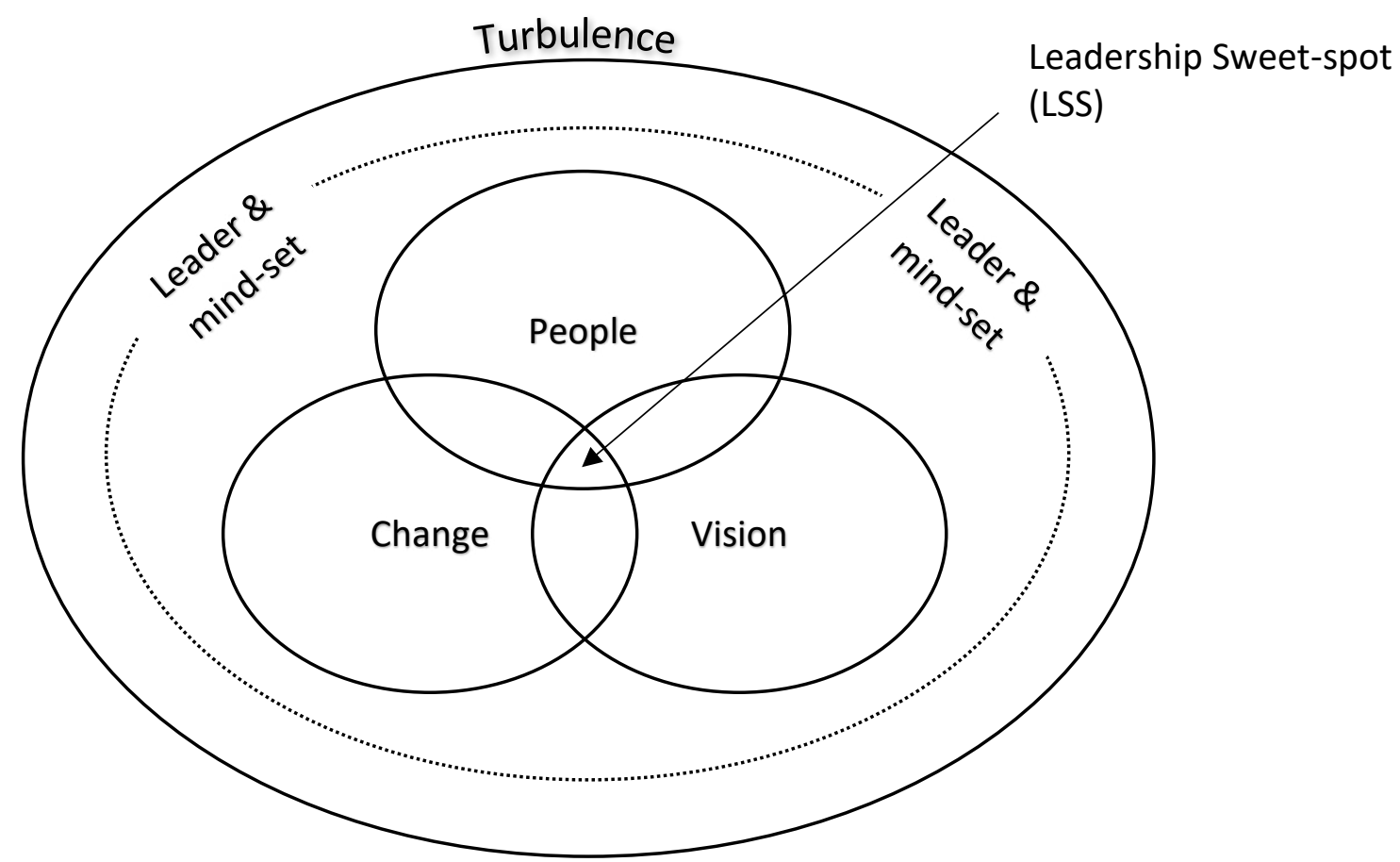

Figure 1: The Five Spheres of Leadership and Leadership Development 
Leadership aligns people with purpose, priorities and resources; good management then takes over to deliver results. The coupling points between leadership and management are the domains of action and mark the transitioning of mind-set from a managerial one to a leadership one (ZIF, 2018). Figure 1 provides a framework for designing, implementing and analysing leadership needs and LD programmes.

\section{EU Capacity Development for ICM}

The EU has an imminent interest in the effectiveness of the EU's Common Security and Defence Policy, and it recognises training as a fundamental component of effectiveness (EEAS, 2017, p. 2). The EU has funded various research projects focusing on capacity development for crisis management, for example PeaceTraining.eu and Whole-of-Society Conflict Prevention and Peacebuilding (WOSCAP) through the Horizon 2020 modality (PeaceTraining.eu, 2018; WOSCAP, 2018). The infrastructure for capacity development of staff, in particular for civilians, working in ICM has developed rapidly in Europe since the end of the Cold War and today there are more than 100 providers (Wolter, et al., 2017). Current professional development includes academic, post-graduate and extra-curricular courses that last from a few hours to several weeks, and are offered in various formats such as online, face-to-face or as blended learning (ESDC, 2018; ZIF, 2018; Patrir, 2018; ASPR, 2018). These courses tend to be content-heavy and primarily focusing on transfer of knowledge and competencies. Some, most notably the Hostile Environment Awareness Training and Training-of-Trainers courses, are also experiential ${ }^{2}$. There is a tendency to prioritise knowledge and skills that are seen directly and immediately relevant for the performance of the job functions. Courses on offer tend to focus on management (Wolter \& Leiberich, 2017, p. 44) and target (potential) senior mission leaders.

Often there are no, or very limited, provisions for professional development beyond predeployment training which is only designed to help trainees to perform basic day-to-day functions. The responsibility for ensuring adequate training of staff serving in EU missions across the gamut of ICM missions 'rests with the contributing authorities, but also with the chain of command' (EEAS, 2017, p. 6). In practice, this means that missions and mission planning staff, begin with the assumption that people to be deployed on mission would have attended at least a pre-deployment training.

The career paths of staff working in ICM are often non-linear and the time spent in one and the same mission limited. This is due not only to the hardship and non-family character of many duty stations, but also to time limits on secondment that are put in place by some contributing authorities which results in quick turnover of staff. There are limited incentives to invest in capacity development as staff typically leave the mission shortly afterwards. Utility of whatever little training occurs is limited since many leadership qualities, particularly the distal and proximal ones like more inclusive mind-sets, leadership intelligences (intellectual, cultural, emotional, intra-personal, transformational, intuitive, body-conscious, environmental) develop over time (Allen \& Gutekunst, 2018, p. 17).

Our survey of current courses highlights a bias towards capabilities and skills and a lesser emphasis on the essential but intangible and abstract areas. Crucial aspects of LD in a VUCA world, such as emotional maturity, are regarded as 'personal' development and thus excluded by the missions or contributing parties. Another reason is the desire for immediate and measurable return on investment to justify value for money. LD in ICM requires general as well as specialised know-how and expertise where the effectiveness of LD Programmes is hard to measure. Organisation engaged in ICM are not (yet) ready to commit to such initiatives and therefore tend to favour developing skills and competencies. To our best knowledge, objective measuring of ROI in LD, beyond Kirkpatrick ${ }^{3}$ level 2, is not practiced 
in ICM. In addition, the EU crisis management operations are often understaffed (Tardy, 2015). In practice this means that the operations and at times the staff themselves do not wish to take part in training since that would mean further absence from their workplace and further increase in their already heavy workloads.

The deficit in leadership due to lack of LD continues and is attributable in part to the motivation of actors engaged in ICM. These actors adapt and learn on the go, generally reactively to external or internal pressures. A recent report concluded that the 'EU's approach to the implementation of peacebuilding and conflict prevention interventions tends to focus on searching for technical solutions to what are often deeply political and complex issues'wicked problems (Borgh, et al., 2017). Research on leadership and complexity shows that today, many leaders beyond the entry level management, are not equipped to deal with the complexity associated with their functions. They do not have the necessary leadership skills and lack the required system perspectives (Rich-Tolsma \& Oliver, 2016; Dawson, 2017; Kegan, 1994; Heifetz, et al., 2009). Consequently, many leaders cannot make decisions that are adequate to the complexity of situations and contexts. In ICM, bad decisions lead to loss of lives and human suffering. The focus on managerial skills and behaviours does not help develop leaders and decision makers able to deal with complexity. Many aspects of ICM do not respond well to reductionist, 'take-it-apart-and-see-how-it-works approaches' (Snowden $\&$ Boone, 2007). Staff in ICM frequently confront wicked problems and operate on the edge of policy where and are expected to deal with extremes of information from absence to overload and required to tackle critical problems (Grint, 2008) in life and death situations. Our example from Bosnia and all complex ICM since, elucidates this point. Decisions need to be made in complex contexts that do not allow for a nuanced understanding of the situation and are marked by interconnectedness of systems, communities and stakeholders. Different cultural values and expectations of colleagues and organisational politics, together with limited human and financial resources, further compound the problem.

\section{LD for ICM: Towards a Whole Person Approach}

LD has professional, relational and personal aspects; and must also recognise drivers and blockers that stem from 'worldviews, emotions, personality traits and dispositional variables' (Woodward, et al., 2019, p. 1.1). Balanced and sustained development along each of the trajectories illustrated in Figure 1 is needed, and can be accelerated through interventions that build on reflective learning (Moon, 2004). There is a growing need to think and operate constructively outside of formal function, across organisational silos and boundaries (Petrie, 2014a), and be able to operate with extremes of information; a conclusion drawn by several independent studies. These observations reinforce the case for moving away from reductionist ideas. Kegan (1982), while arguing that a focus on knowledge and competencies is relevant, suggests that it is insufficient, because the ability to deal with complexity is correlated with a person's state of mind. Kegan and Lahey (2009) demonstrate that at times leaders' current state of mind does not allow them to behave differently, because they hold competing commitments or assumptions that are driving their behaviours. In these cases, the real limiting factor is not the leader's knowledge; it is the leader's mind, how they make meaning of the world and conflicting values. For leaders to increase their ability to deal with complexity, they need to modify, enlarge the way they give meaning to life. In this process, values and basic assumptions must shift. This is critically important in the adaptive change process, where a leader develops a more sophisticated mind-set (Heifetz, et al., 2009; Bushe \& Marshak, 2016; Kegan \& Lahey, 2009) which allows the leader to pursue a set of goals and perspectives that appeared to be contradictory in their earlier mind-set. In other words, the leader's capacity for holding — coping and dealing with — ambiguity needs to grow. 
We draw on 'theories in use', instruments and practices that support the shift of basic assumptions that we have described above and include hierarchical complexity of thinking (Dawson, 2017), Street Smart Awareness (Allen \& Gutekunst, 2018), Torbert's Action Inquiry (2004; Erfan \& Torbert, 2015), Leadership Circle $360^{\circ}$ Profiling (TLC, 2018), Senge's Fifth Discipline (2006), Adaptive Leadership (Heifetz \& Linsky, 2002; Heifetz, et al., 2009), and Petrie's Vertical LD (2014b) to name a few. These theory-based, yet highly practical approaches are not an exhaustive list and while such approaches sit well in various spheres and areas of overlap in WPA, they are underpinned by certain prerequisites. Sitting within the leader sphere, these are a broad set of individual qualities that underpin sensemaking ability. This sphere sits within context but outside of the inner Venn in Figure 1. Leaders draw unique meaning from each of the spheres, particularly the overlapping areas, because of their world-view. The contingencies and constraints that emerge are themselves in a state of flux (Bushe \& Marshak, 2016, pp. 63-64). These prerequisites and the sphere of WPA they relate to are discussed below.

\section{Self-awareness}

The leadership journey begins with self-knowledge and self-awareness (Rosenbach, 2018). Perhaps the single most relevant practice in this area for the myriad leaders who suffer from high workload and high-paced lifestyle is to slow down and deliberately create open spaces where reflection is possible. A useful set of tools at individual and collective level is Street Smart Awareness (Allen \& Gutekunst, 2018) which we will discuss later. Self-awareness work also implies learning how to uncover our often hidden and limiting mental models, including those that Kegan and Lahey call 'big assumption' and replace them using tools such as Immunity to (2009). Another useful tool for self-awareness is Action Inquiry (Erfan \& Torbert, 2015; Torbert, 2004). Leadership Circle $360^{\circ}$ profile developed by Anderson et al. is a sophisticated tool that provides a comprehensive framework for using feedback to generate self-awareness that can strengthen creative competencies that drive leadership effectiveness. It analyses the deeper patterns beneath every-day behaviour in the workplace and enables them to identify the pathway for sustainable, effective change. Unlike other $360^{\circ}$ instruments, TLC makes a distinction between creative leadership competencies and reactive tendencies that hold leaders back (TLC, 2018). There are now several instruments in the market that allow for assessing the complexity of thinking and mind-sets of leaders. Among our favourite ones are the Lectica TM Decision Making Assessment (LDMA), the Leadership Circle $360^{\circ}$ profile and the Global Leadership Profile. The LDMA, part of the Lectica suite is a learning tool that supports the development of leaders' decision-making skills. The assessment presents a real-world workplace dilemma, followed by a series of questions that ask leaders to discuss the nature of the problem, describe solutions, compare these solutions, and describe decision-making processes for similar situations. The LDMA focuses on three aspects: collaborative capacity - the ability to bring together diverse perspectives for inclusive, innovative, and effective solutions; contextual thinking: the ability to consider problems within the broader systems and contexts in which they are embedded; and cognitive complexity: the ability to think well about complex issues. LDMA is a formative assessment that provides the leader with an understanding of their current way or reasoning and how they would likely see the world from the next level (Lectica, 2018).

\section{Learning ability}

Our ability to learn robustly and continuously in learning cycles that consist of goal setting, information gathering, application, feedback and reflection is essential for growth. Robust learning and sense making allow leaders to step outside their box, to a space where new knowledge can be linked to existing understanding and tested in real-world contexts, to 
provide solid foundations for future learning (Dawson, 2017). Knowledge correlates with good leadership; however, Gurteen argues that 'explicit knowledge, tacit knowledge, information, experience and skill are not enough to make knowledge productive' (1998, pp. $5-6)$; it is how that knowledge is managed within an individual or an organisation that leads to creativity and innovation (pp. 12-13). Putting knowledge into action requires competence but more significantly, the right motivation and positive attitude (p. 5).

\section{Relationships}

The third prerequisite is collaboration skills and the ability to work with others who represent a wide range of perspectives and areas of expertise. The term relational leadership attempts to move beyond 'static exchanges and address dynamic leadership relationships within organizational contexts' (Antonakis \& Day, 2018, p. 111). In a VUCA world, relationships are critical; leaders need to embrace complexity as opportunity, value collaboration and develop a network mind-set. As scholarship on relational leadership grows, robust tools for diagnosing and developing relationships should follow that take a multidisciplinary longitudinal view of relationships focusing on both process and actors (Day, 2014; Uhl-Bein \& Ospina, 2012). One of the lessons we draw from military leadership is that strong relationships over time contribute to influencing, facilitate "jointness" and encourage collaboration towards developing common perspectives and robust solutions. These lessons are equally applicable, if not more so, in crises management, peacebuilding and development.

\section{Scaffolding for contextual thinking and decision making under complexity}

Leaders also need to learn how to use a wide range of tools to scaffold our contextual thinking and decision-making under complexity. A range of tools can support leaders in this. When dealing with complexity, the Cynefin framework, a conceptual framework that draws on systems theory, complexity theory, network theory and learning theories, can be used to aid decision-making (Snowden \& Boone, 2007). The framework sorts issues facing leaders into four decision-making domains: obvious, complicated, complex, chaotic and a centre of disorder when an issue cannot be located within a decision-making domain. Each domain reflects different relationships between cause and effect, which implies different conceptual understanding and the need for adaptive leadership and to apply different tools and practices towards leadership decisions - the Leadership Sweet-spot of the Whole Person Approach.

\section{Emotional and body-based intelligence}

Neuroscience research tells us that our memories, fears, and ambitions are not just stored in our head but carried in the cells of our bodies, that "the mind is embodied, not just enskulled" (Siegel, 2012, p. 5). To help adults develop and evolve, the most direct path may not be through the head but through the body (Petrie, 2015, p. 20). Mindfulness exercises, meditation, yoga and various martial arts are widely accepted practices in the West that combine meditation and movements. Managing emotions and access to body-based intelligence, are in our experience the most challenging aspects of LD. In our opinion, the key reasons for this lies in the fact that connecting with our emotions and bodies also means that we deal with our old traumas and projections. Nonetheless, this is necessary for developing higher self-awareness, empathy, ability to connect with others and understand the beat of the system.

\section{Applications of Whole Person Approach}

WPA provides a powerful vehicle for leadership needs assessment, leadership evaluation, and leadership programme design, and can help human resource professionals to make informed decisions about leadership development in organisations. WPA is adaptive and can be 
tailored to incorporate situations and perceived needs for mid to long-term contingencies; at the same time, the approach can address beyond-the-horizon leadership needs in a complex world. The approach is premised on relational dialectics, individual and social constructs, organisational contexts and other influences within a complex adaptive system. It is about creativity, innovation and as such non-prescriptive; we encourage use of existing tools and instruments as well as experimentation, combined with formative assessment tools to support leaders and leadership development. Applying the framework and positioning various specific interventions in each of the spheres of WPA is beyond the scope of this exploratory paper; only the conceptual contours are advanced here. A hypothetical example of how WPA may translate in to programme design is shown in Table 1. Programme monitoring and evaluation, gap analysis, needs assessment and personal development plans are some of the other ways in which organisations and individuals could apply WPA.

\section{Conclusion}

Hyper-change places greater premium on leaders and their ability to adapt themselves and the organisations they lead. In the international and multi-agency landscape of peacebuilding and development, WPA provides a powerful mechanism for LD at many levels. Applied as a framework, WPA provides both a conceptual and a practical tool for monitoring, evaluating and developing human capital needs in organisations. Because WPA aims at the leader and the leadership collective, which in our conception of Leadership Sweet-spot includes followers and co-leaders, the approach provides a unifying logic to organisational development. We believe there is great potential to develop not just programmes and evaluations but general and specific tools and approaches using WPA. This research questions the foundations of contemporary LD approaches in peace and development studies and opens the door for wider as well as pointed research on aims, objectives, design and process of LD. We emphasise that while we have used ICM as a context, WPA is equally relevant across other sectors too. WPA is adaptive, allowing leaders to take charge of their own development, draw on programmes and concepts relevant to their particular industry while also drawing on relevant cross-sector offerings.

\footnotetext{
${ }^{1}$ The model is based on a framework introduced by Dr Zaidi (2015) for leadership short course design and applied to the UK Ministry of Defence Strategic Leadership Programme.

${ }^{2}$ For a detailed discussion and thematic overview of courses, see Wolter et al. (2017).

${ }^{3}$ The degree to which participants acquire the intended knowledge, skills, attitude, confidence and commitment based on their participation in the training (Kirkpatrick Partners, n.d.)
} 
Table 1: Example of LD Content, Tools and Frameworks using WPA for Programme Design

\begin{tabular}{|c|c|c|c|c|c|c|}
\hline \multicolumn{2}{|c|}{ WPA Sphere } & Turbulence & $\begin{array}{l}\text { Leader \& } \\
\text { Mind-set }\end{array}$ & People & Visions & Change \\
\hline \multirow{3}{*}{ 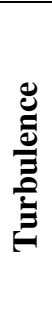 } & Theory & $\begin{array}{l}\text { Complexity } \\
\text { Theory }\end{array}$ & $\begin{array}{l}\text { Self-awareness } \\
\text { Multiple } \\
\text { intelligences }\end{array}$ & $\begin{array}{l}\text { Relational } \\
\text { Leadership } \\
\text { LMX }\end{array}$ & $\begin{array}{l}\text { Stakeholder } \\
\text { Analysis } \\
\text { Power Analysis }\end{array}$ & $\begin{array}{l}\text { Change Theory } \\
\text { Organisational } \\
\text { Culture }\end{array}$ \\
\hline & Practice & PESTLE & SWOT & MBTI (Others) & Risk Mapping & $\begin{array}{l}\text { McKinsey 7S } \\
\text { Force Field } \\
\text { Analysis }\end{array}$ \\
\hline & Reflection & $\begin{array}{l}\text { Power and } \\
\text { Influence }\end{array}$ & $\begin{array}{l}\text { Discussion and } \\
\text { focus groups }\end{array}$ & $\begin{array}{l}\text { Reflective } \\
\text { practice }\end{array}$ & $\begin{array}{l}\text { Complexity } \\
\text { Theory }\end{array}$ & Schein's Model \\
\hline \multirow{3}{*}{ 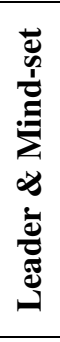 } & Theory & & $\begin{array}{l}\text { MBTI (Self); } \\
\text { Psychometric } \\
\text { Tests }\end{array}$ & $\begin{array}{l}\text { SIT } \\
\text { Leadership } \\
\text { intelligences }\end{array}$ & $\begin{array}{l}\text { Bridges } \\
\text { Self-awareness }\end{array}$ & $\begin{array}{l}\text { Vertical } \\
\text { development }\end{array}$ \\
\hline & Practice & & Kirkpatrick & $\begin{array}{l}\text { Leadership } \\
\text { Circle }\end{array}$ & $\begin{array}{l}\text { SWOT } \\
\text { PESTLE }\end{array}$ & Futures wheel \\
\hline & Reflection & & Johari Window & 360 Repotting & $\begin{array}{l}\text { Collaboration } \\
\text { Feedback }\end{array}$ & $\begin{array}{l}\text { Self- } \\
\text { management } \\
\text { and regulation }\end{array}$ \\
\hline \multirow{3}{*}{ 20 } & Theory & & & $\begin{array}{l}\text { Cognitive } \\
\text { Biases }\end{array}$ & $\begin{array}{l}\text { Adaptive } \\
\text { Leadership }\end{array}$ & $\begin{array}{l}\text { Resistance to } \\
\text { change }\end{array}$ \\
\hline & Practice & & & Culture; Social & $\begin{array}{l}\text { Lewin's } 3 \\
\text { Stage Model }\end{array}$ & $\begin{array}{l}\text { Organisational } \\
\text { Culture }\end{array}$ \\
\hline & Reflection & & & RLT & $\begin{array}{l}\text { Feedback and } \\
\text { discussions }\end{array}$ & Mind-sets \\
\hline \multirow{3}{*}{ : } & Theory & & & & Value System & Risk Mapping \\
\hline & Practice & & & & $\begin{array}{l}\text { Strategy } \\
\text { Development }\end{array}$ & Measurement \\
\hline & Reflection & & & & $\begin{array}{l}\text { Strategy } \\
\text { analysis }\end{array}$ & Futures wheel \\
\hline \multirow{3}{*}{ 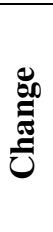 } & Theory & & & & & Change Theory \\
\hline & Practice & & & & & Change models \\
\hline & Reflection & & & & & Futures wheel \\
\hline \multirow{3}{*}{ 20 } & Theory & \multicolumn{5}{|c|}{ Vertical Development; Complexity Leadership; Adaptive Leadership; LSS } \\
\hline & Practice & \multicolumn{5}{|c|}{ War-gaming and Role Play; Sheep dipping; 360 appraisals etc. } \\
\hline & Reflection & \multicolumn{5}{|c|}{ Leadership Agility Model; Introspection; Value based leadership } \\
\hline
\end{tabular}

An example of the range education, training, coaching and assessments for WPA as part of a hypothetical ICM LD Programme Design. The matrix addresses the what and alludes to the how; however, not shown here, is the overarching-question 'why?' that would invariably be the starting point for programme design.

Dr Zaidi is a lecturer in Leadership and Strategy at Cranfield University. He is currently the Academic Director for UK Ministry of Defence Strategic Leadership Programme and has 
delivered leadership courses in over 40 countries. Dr Zaidi served in the military before joining academia.

Dr Blanka Bellak is Director of Leadership Associates, a social enterprise that specializes in vertical LD and in gender aspects of leadership. A former Director of ASPR, a UNESCOaward winning centre on peace and conflict, Blanka has 20 years of experience in international security and development. 


\section{References}

Allen, J. \& Gutekunst, H., 2018. Street Smart Awareness and Inquiry-in-Action. Helsinki: Amara Collaboration.

Allen, P., 2018. Complex Evolving Social Systems: Unending, Imperfect Learning. In: E. Mitleton-Kelly, A. Paraskevas \& C. Day, eds. Handbook of Research Methods in Complexity Science: Theory and Applications. Cheltenham: Edward Elgar, pp. 18-44.

Antonakis, J. \& Day, D. V., 2018. Introduction. In: J. Antonakis \& D. V. Day, eds. The Nature of Leadership. London: Sage, pp. 3-26.

ASPR, 2018. Austrian Study Centre for Peace and Conflict Resolution. [Online]

Available at: https://www.aspr.peacecastle.eu/

[Accessed 0711 2018].

Atree, L., Street, J. \& Venchiarutti, L., 2018. United Nations peace operations in complex environments: Charting the right course, London: Saferworld.

Barber, H. F., 1992. Developing Strategic Leadership: The US Army War College Experience. Journal of Management Development, 11(6), pp. 4-12.

Bass, B. M., 1985. Leadership and performance beyond expectations. New York: Free Press .

Bennins, W. \& Nanus, B., 1985. Leaders: Strategies for Taking Charge. 1st ed. New York: Harper Collins.

Bennis, W. \& Goldsmith, J., 2010. Learning to Lead: A Workbook on Becoming a Leader. 4th ed. New York: Basic Books.

Blanchard, K., Carew, D. \& Carew, E. P., 2000. The One Minute Manager Builds High Performing Teams. London: Harper Collins.

Borgh, C. V. D., Martin, M. \& Bojicic Dzelilovic, M., 2017. EU capabilities in conflict prevention and peacebuilding: Challenges, strengths and opportunities of a Whole-of-Society approach, Utrecht/London: Utrecht University and London School of Economics and Political Science. 
Bushe, G. \& Marshak, R., 2016. The Dialogic Mindset: Leading Emergent Change in a Complex World. Organisatonal Development, 34(1), pp. 37-65.

Dawson, T., 2017. The Complexity Gap. [Online]

Available at: https://medium.com/@ theo_dawson/the-complexity-gap-faad87e0bb5f [Accessed 15 October 2018].

Day, D. V., 2014. Time and leadership. In: A. J. Shipp \& Y. Fried, eds. Time and work. New York: Psychology Press, pp. 30-52.

Edwards, G., Elliott, C., Iszatt-White, M. \& Schedlitzki, D., 2013. Critical and alternative approaches to leadership developemnt. Management Learning, 44(1), pp. 3-10.

EEAS, 2017. EU Policy on Training for CSDP, Brussels: European External Action Service.

Erfan, A. \& Torbert, B., 2015. In: H. Bradbury, ed. Sage Handbook of Action Research. 3rd ed. London: Sage, pp. 64-75.

ESDC, 2018. European Security and Defence College. [Online]

Available at: https://eeas.europa.eu/topics/common-security-and-defence-policy-csdp/4369 [Accessed 611 2018].

Genovese, M. A., 2016. The Future of Leadership. Hove: Taylor and Francis.

Gibson, C. A. \& Tarrant, M., 2010. A 'Conceptual Models' Approach to Organisational Resilience. The Australian Journal of Emergency Management, 25(2), pp. 6-12.

Grint, K., 2008. Wicked Problems and Clumsy Solutions: the Role of Leadership. Clinical Leader, I Number II(II), pp. 11-15.

Gronn, P., 2000. Distributed properties: a new architecture for leadership. Educational Management Administration \& Leadership, , Volume 28, p. 317-338..

Gurteen, D., 1998. Knowledge, Creativity and Innovation. Journal of Knowledge Management, 2(1), pp. 5-13.

Guterres, A., 2018. Secretary-General's Address to the General Assembly on 25 September 2018. New York, United Nations. 
Heifetz, R. A. \& Linsky, M., 2002. Leadership on the line: Staying alive through the dangers of leading. Boston, Mass: Harvard Business School Press.

Heifetz, R., Grashow, A. \& Linsky, M., 2009. The Practice of Adaptive Leadership: Tools and Tactics for Changing Your Organization and the World. Boston: MA: Harvard Business School.

Houben, M., 2005. International Crisis Management: The Approach of European States. London: Routledge.

International Forum for the Challenges of Peace Operations, 2010. Considerations for Mission Leadership in United Nations Peacekeeping Operations, Stockholm: Edita Västra Aros AB.

Kaufmann, C., 1996. Possible and Impossible Solutions to Ethnic Civil Wars. International Security, 20(4), pp. 136-175.

Kegan, R., 1982. The evolving self: Problem and process in human development. Cambridge, MA: Harvard University Press.

Kegan, R., 1994. In over our heads: The mental demands of modern life. Cambridge(MA): Harvard University Press.

Kegan, R. \& Lahey, L., 2009. Immunity to Change:How to overcome and unlock potential in your self and your organisation. Boston: Harvard Business Press.

Kirkpatrick Partners, n.d. The Kirkpatrick Model. [Online] Available at: https://www.kirkpatrickpartners.com/Our-Philosophy/The-Kirkpatrick-Model [Accessed 2 November 2018].

Kotter, J., 2001. What Leaders Really Do?. Harvard Business Review, December.

Kotter, J. P., 2012. Leading Change. Cambridge: MA: HBR Press.

Latham, J. R., 2014. Leadership for Quality and Innovation: Challenges, Theories, and a Framework for Future Research. Quality Management Journal, 21(1), pp. 11-15. 
Lectica, 2018. The LDMA. [Online]

Available at: https://dts.lectica.org/_about/showcase.php?instrument_id=LDMA

[Accessed 18 October 2018].

Lichtenstein, B. B. et al., 2006. Complexity leadership theory: An interactive perspective on leading in complex adaptive systems. $E: C O, 8(4)$, pp. 2-12.

McLay, A., 2014. Re-reengineering the dream: agility as competitive adaptability. International Journal of Agile Systems and Management, 7(2), pp. 101-115.

Merkelbach, M., 2017. Voluntary Guidelines on the Duty of Care to Seconded Civilian Personnel, Bern, London, Berlin: Swiss Federal Department of Foreign Affairs, Stabilisation Unit, Center for International Peace Operations.

Mojzes, P., 2016. Yogoslavian Inferno: Ethnoreligious Warfare in the Balkand, London: Bloomsbury Academic.

Moon, J. A., 2004. A Handbook of Reflective and Experiential Learning: Theory and Practice. Abingdon: Routledgefalmer.

Nadler, D. A. \& Tushman, M. L., 1990. Beyond the Charismatic Leader: Leadership and Organizational Change. California Management Review, 32(2), p. 77-97.

Northouse, P. G., 2019. Leadership:Theory and Practice. 8th ed. Los Angles: Sage.

Oddou, G. R. \& Mendenhall, G. R., 2018. Global Leadership Development: Processes and Practices. In: M. E. Mendenhall, et al. eds. Global Leadership: Practice, Research, and Development. Abingdon: Routledge, p. Chapter 8.

OECD, 2001. Public Sector Leadership in the 21st Century, Paris: OECD Publications.

Patrir, 2018. Patrir. [Online]

Available at: http://patrir.ro/en/

[Accessed 0711 2018].

PeaceTraining.eu, 2018. PeaceTraining.eu. [Online]

Available at: https://www.peacetraining.eu/

[Accessed 411 2018]. 
Petrie, N., 2014a. Future Trends in Leadership Development, Colorado Springs: Centre for Creative Leadership.

Petrie, N., 2014b. Vertical Leadership Development-Part 1: Developing Leaders for a Complex World, Colorado Springs: Centre for Creative Leadership.

Petrie, N., 2015. The How-To of Vertical Leadership Development-Part 2, Colorado Springs: Centre for Creative Leadership.

Rich-Tolsma, M. \& Oliver, J., 2016. Addressing the Complexity Gap: Developing Integrated Thinking Skills at Board Level. Board Leadership: Innovative Approached to Governance, January - February, 2016(143), pp. 1-3, 8.

Rittel, H. W. J. \& Webber, M. M., 1973. Dilemmas in a General Theory of Planning. Policy Sciences, 4(2), pp. 155-169.

Rosenbach, W., 2018. Contemporary Issues in Leadership. 7th ed. Abingdon: Routledge.

Santana, L. C., 2009. Makind Developemnt Visible: A sequential mixed methodd study of integral impac of of post-classroom leader and leadership developemnt. s.1.:Antioch University.

Senge, P. M., 2006. The Fifth Discipline. London: Random House.

Siegel, D. J., 2012. The Developing Mind: How Relationships and the Brain Interact to Shape Who We Are. 2nd ed. New York: Guilford Press.

Snowden, D. J. \& Boone, M. E., 2007. A Leader's Framework for Decision Making. HBR, Volume November.

Tal, D. \& Gordon, A., 2016. Leadership of the present, current theories of multiple involvements: A bibliometric analysis. Scientometrics, Volume 107, pp. 259-269.

Tano, M. L., 2006. Developing agile tribal leaders and agile tribal institutions to adaptively manage and mitigate the impacts of global climate change in indian country, Denver: CO: International Institute of Indeginous Resource Management.

Tardy, T., 2015. CSDP in action: What contribution to international security, Paris: EU Institute for Security Studies. 
Tardy, T. et al., 2017. Recasting EU Civilian Crisis Management, Paris: EU Institute for Security Studies.

TLC, 2018. The Leadership Circle. [Online]

Available at: https://eu-en.leadershipcircle.com/

[Accessed 18 October 2018].

Torbert, B., 2004. Action Inquiry: The Secret of Timely and Transforming Leadership. San Francisco: Barret Koehler.

Uhl-Bein, M., 2006. Relational leadership theory: Exploring the social processes of leadership and Organising. The Leadership Quarterly, 17(6), pp. 654-676.

Uhl-Bein, M. J. \& Ospina, X., 2012. s.1., s.n.

Uhl-Bein, M., Marion, R. \& McKelvey, B., 2007. Complexity Leadership Theory: Shifting leadership from the Indictrial Age to the Knowledge Era. The Leadership Quarterly, Volume 18, pp. 298-311.

Watters, B. S. C., 2019. Leadership in the 'Wicked' Problem of Bosnia's civil war: A case study examining ethical decision making under duress. Leadership, 15(1), pp. 3-26.

Wolter, S. \& Leiberich, A. M., 2017. Baseline research and stakeholder report on conflict prevention and peacebuilding training, Vienna: PeaceTraining.eu.

Wolter, S., Tanase, A., Brand Jacobsen, K. \& Curran, D., 2017. Existing Peacebuilding and Conflict Prevention Curricula Report, Vienna: PeaceTraining.eu.

Woodward, I. C., Shaffakat, S. \& Dominé, V. H., 2019. Exploring Leadership Drivers and Blockers, Singapore: Palgrave Macmillan.

World Bank, 1997. The State in a Changing World, New York: Oxford University Press.

WOSCAP, 2018. WOSCAP. [Online]

Available at: https://www.woscap.eu/home

[Accessed 511 2018]. 
Zaccaro, S. J., 2002. Organisational Leadership and Social Intelligence. In: R. E. Riggio \& S. E. Murphy, eds. Multiple Intelligences and Leadership (Organi... (Paperback)by . New Jersey: s.n., pp. 28-54.

Zaccaro, S., Kemp, C. \& Bader, P., 2004. Leader traits and attributes. In: The Nature of Leadership. ThousandOaks, CA: Sage, pp. 101-124.

Zaidi, I., 2015. Leadership Development in Defence. Shrivenham: Cranfield University.

ZIF, 2018. The Art of Leadership in Peace Operations. [Online]

Available at: http://www.zif-berlin.org/de/training-

vorbereitung/trainingskurse/spezialisierungskurse/leadership.html

[Accessed 0711 2018].

Zyl, E. V., 2019. The Nature and Meaning of Peace Leadership. In: E. V. Zyl \& A. Campbell, eds. Peace Leadership: Self Transformation to Peace. Randburg: KR Publishing. 